\title{
Three new Drosophilidae species records for South Africa
}

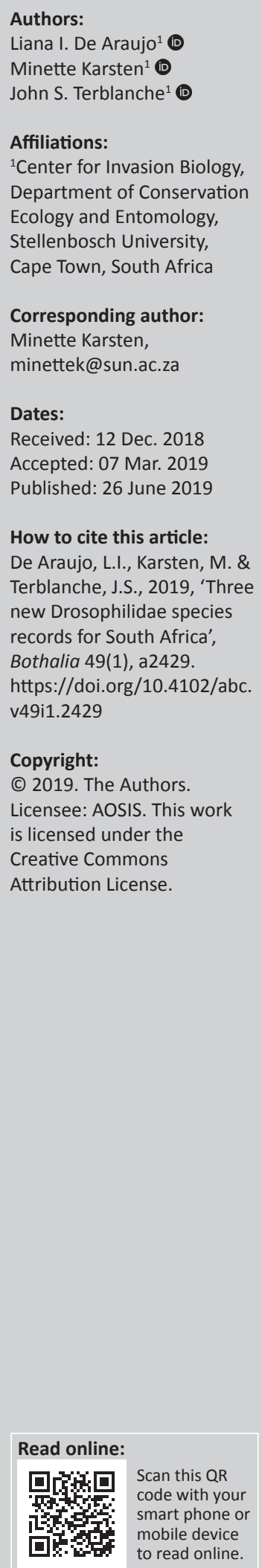

Background: Data on the current species diversity from the Drosophilidae family in South Africa is limited or outdated.

Objectives: Using haphazard, limited trapping for a different study, we serendipitously report on and document Drosophilidae species in two distinct regions (representing a sub-tropical and a Mediterranean climate region) of South Africa.

Method: Drosophilidae were trapped using mixed fruit and mushroom traps around urban areas in two climatically distinct regions of South Africa. The flies were identified using standard barcoding (Cytochrome c Oxidase Subunit I [COI] gene sequence) and, in some cases, additional identification from a taxonomical expert using morphological traits. Species were checked against literature, online resources and a previously compiled library of South African Drosophilidae to determine whether they were new records.

Results: Thirteen species were readily collected and identified. Of these, three species (Drosophila ananassae, Drosophila nasuta and Zaprionus taronus) have not been reported previously in South Africa. One of the species (Z. taronus) was captured in a home garden, while the other two species were captured in an urban-agricultural region with a sub-tropical climate.

Conclusions: From our limited serendipitous sampling, three new species records have been found in sub-tropical climates in South Africa. With more comprehensive, systematic sampling, a better understanding of the South African Drosophilidae composition, and thus the detection of alien or invasive species, can be pursued. Baseline data for understanding spatio-temporal patterns of native biodiversity, or for informing management actions in the case of alien or invasive species, are currently inadequate for this group in the region.

Keywords: Drosophilidae; Zaprionus; Drosophila; COI; barcoding.

\section{Background}

Insects in the family Drosophilidae, commonly known as vinegar flies, are used as model systems for a diverse range of research fields, especially medicine (Hewitt \& Whitworth 2016). More recently, there has been growing concern surrounding invasive or pest Drosophilidae species in South Africa, as several invasive Drosophilidae species have been detected in other parts of the world and can target ripe soft-bodied fruit, resulting in economic losses for the agriculture sector (Farnsworth et al. 2017). Consequently, current species composition, and spatial and temporal patterns of Drosophilidae biodiversity are important baseline information. South African Drosophilidae are a case in point: there is surprisingly poor current knowledge of Drosophilidae species diversity, geographic range extent of common or rare species or how dynamic population abundances are in this group (McEvey, Potts \& Rogers 1988; Tsacas 1990). Furthermore, what little information is available is likely outdated or not necessarily representative of the different regions of the country. The most recent, scattered records show 76 species in the country documented between 1900 and 2013 in an unpublished document updated in 2016 and provided by Dr Shane McEvey (Australian Museum Research Institute), while the most recent accessible published data indicate 70 known species from South Africa (Tsacas 1990). From the unpublished document, more recent records include D. immigrans (2010), D. simulans (2013), D. punctatonervosa (2013) and Scaptomyza oxyphallus (2013). Although an invasive drosophilid species, D. flavohirta (1983), has been recorded in South Africa previously, no recent information regarding this species' abundance or its potential impacts on native biodiversity is available (Tsacas 1990). 


\section{Methods}

Drosophilidae species were sampled sporadically in two urban-agricultural regions of South Africa using fruitfilled bucket traps (Table 1) for a different project, but also aimed at generating biodiversity knowledge. Species were identified using the Universal cytochrome oxidase I (COI) primers (LCO1490 and HCO2198; Folmer et al. 1994) by InqabaBiotech ${ }^{\mathrm{TM}}$ and the South African Sugarcane Research Institute's (SASRI) biotechnology department. PCR conditions were an initial denaturation of $5 \mathrm{~min}$ at $94^{\circ} \mathrm{C}$, followed by 35 cycles of $30 \mathrm{~s}$ denaturation at $94^{\circ} \mathrm{C}, 30 \mathrm{~s}$ annealing at $50^{\circ} \mathrm{C}$ and $60 \mathrm{~s}$ of extension at $68^{\circ} \mathrm{C}$, and a final elongation at $68^{\circ} \mathrm{C}$ for $10 \mathrm{~min}$. Sequences were aligned and edited in BioEdit (Hall 1999) and closest sequence matches obtained using BLAST (Altschul et al. 1997) in NCBI. Morphology of some species was confirmed against relevant species identification keys (Yassin \& David 2010). Positive matches were downloaded to include in a phylogenetic tree to confirm identification based on both neighbour-joining (NJ) and maximum likelihood (ML) methods using MEGA X (Kumar et al. 2018). The resulting trees were similar, and therefore we only show the tree based on ML (Figure 1).

\section{Results}

Once species were identified, it was evident that some species had no prior published records regarding their occurrence in South Africa (Tsacas 1990). TaxoDros was also consulted and showed no records for some species in South Africa. This was the case for three species, namely Drosophila ananassae (Figure 2a), D. nasuta (no image available) and Zaprionus taronus (Figure 2h). Zaprionus taronus has never before been reported from South Africa (McEvey, pers. comm.); however, this species is surrounded by ongoing taxonomic uncertainty. Zaprionus taronus is probably not invasive and more likely overlooked or previously mis-identified as it has a confirmed Afrotropical distribution (Yassin \& David 2010). The expertise of the person doing the identification, how the determination was made and what material was used for the determination are key information that needs to be established. Prigent, Suwalski and Veuille (2017) and Yassin et al. (2010) have highlighted the importance of sequence data to establish species delineation in the Drosophilidae.

Zaprionus taronus was recorded in a home garden in Stellenbosch, Western Cape province, South Africa, while the other two species were sampled near buildings at the South African Sugarcane Research Institute in Mount Edgecombe, KwaZulu-Natal province. We are unable to determine whether these species should be classified as alien or invasive as there is limited data covering Drosophilidae species' historical native distributions in the region. The current distribution of D. ananassae is cosmopolitan, while D. nasuta largely occurs in the Afrotropical region and south Asia (Brake \& Bächli 2008 cited in Vilela \& Goñi 2015). The species collected were bycatch from another research study, and thus the bait variety was quite restrictive and sample sites selective; therefore, this may be the reason for the exclusion of other more commonly reported South African drosophilids (e.g. Z. capensis). A single sampling site has been provided per species as the primary project only required a single site per species.

TABLE 1: The locations and description of collection sites, date of capture, method of identification (ID; by COI barcode [Sequence], by Drosophila expert [expert], identified by author using morphological keys [morphology]), bait type and National Center for Biotechnology Information (NCBI) accession numbers for the 13 Drosophilidae species collected in our study in South Africa.

\begin{tabular}{|c|c|c|c|c|c|c|c|c|c|}
\hline Species & Bait & $\begin{array}{c}\text { Latitude } \\
\text { (decimal } \\
\text { degrees, }^{\circ} \mathrm{S} \text { ) }\end{array}$ & $\begin{array}{c}\text { Longitude } \\
\text { (decimal } \\
\text { degrees, }^{\circ} \mathrm{E} \text { ) }\end{array}$ & Site description & Climate & $\begin{array}{c}\text { Date of } \\
\text { capture } \\
\text { (dd/mm/yy) }\end{array}$ & ID & $\begin{array}{l}\text { Sub- } \\
\text { mission \# }\end{array}$ & $\begin{array}{l}\text { 1st for Republic } \\
\text { of South Africa }\end{array}$ \\
\hline Drosophila ananassae & $\begin{array}{l}\text { orange and } \\
\text { lemon mix }\end{array}$ & -29.7062 & 31.0444 & Urban & Sub-tropical & $22 / 03 / 18$ & Sequence & 2172994 & yes \\
\hline Drosophila busckii & avocado & -33.8956 & 18.5642 & Home garden & Mediterranean & $02 / 11 / 17$ & Sequence & 2172984 & no \\
\hline Drosophila funebris & banana & -33.3465 & 19.6232 & $\begin{array}{l}\text { Mountain/ Nature } \\
\text { Reserve }\end{array}$ & Mediterranean & 09/01/18 & Sequence & 2172997 & no \\
\hline Drosophila hydei & $\begin{array}{l}\text { mushroom, } \\
\text { banana, orange }\end{array}$ & -33.8956 & 18.5642 & Home garden & Mediterranean & $11 / 10 / 17$ & $\begin{array}{l}\text { Sequence, } \\
\text { expert }\end{array}$ & 2172999 & no \\
\hline Drosophila immigrans & banana & -33.8956 & 18.5642 & Home garden & Mediterranean & $02 / 11 / 17$ & $\begin{array}{l}\text { Sequence, } \\
\text { expert }\end{array}$ & 2172876 & no \\
\hline Drosophila melanogaster & banana, orange & -29.7013 & 31.1009 & Coastal forest & Sub-tropical & 08/06/18 & Sequence & 2172890 & no \\
\hline Drosophila nasuta & $\begin{array}{l}\text { orange and } \\
\text { lemon mix }\end{array}$ & -29.7062 & 31.0444 & Urban & Sub-tropical & $22 / 0318$ & Sequence & 2173275 & yes \\
\hline Drosophila simulans & orange & -33.8956 & 18.5642 & Home garden & Mediterranean & $02 / 11 / 17$ & $\begin{array}{l}\text { Sequence, } \\
\text { expert }\end{array}$ & 2173001 & no \\
\hline Drosophila yakuba & $\begin{array}{l}\text { orange and } \\
\text { lemon mix, } \\
\text { banana }\end{array}$ & -29.7062 & 31.0444 & Urban & Sub-tropical & $22 / 03 / 18$ & Sequence & 2173281 & no \\
\hline Zaprionus indianus & banana & -29.7062 & 31.0444 & Urban & Sub-tropical & $22 / 03 / 18$ & Sequence & 2173002 & no \\
\hline Zaprionus taronus & lemon & -33.9353 & 18.8907 & $\begin{array}{l}\text { Home vegetable } \\
\text { garden }\end{array}$ & Mediterranean & $16 / 11 / 17$ & Sequence & 2172892 & yes \\
\hline Zaprionus tuberculatus & banana & -29.7062 & 31.0444 & Urban & Sub-tropical & $22 / 05 / 18$ & $\begin{array}{l}\text { Sequence, } \\
\text { morphology }\end{array}$ & 2173286 & no \\
\hline Zaprionus vittiger & mango & -33.9365 & 18.8657 & Botanical garden & Mediterranean & $20 / 10 / 17$ & Sequence & 2173266 & no \\
\hline
\end{tabular}

Note. The final column indicates whether this species has any previous records in South Africa by indicating a 'no' if it has been recorded before and a 'yes' if there is no previous record. The species with first records for South Africa are indicated in bold. 


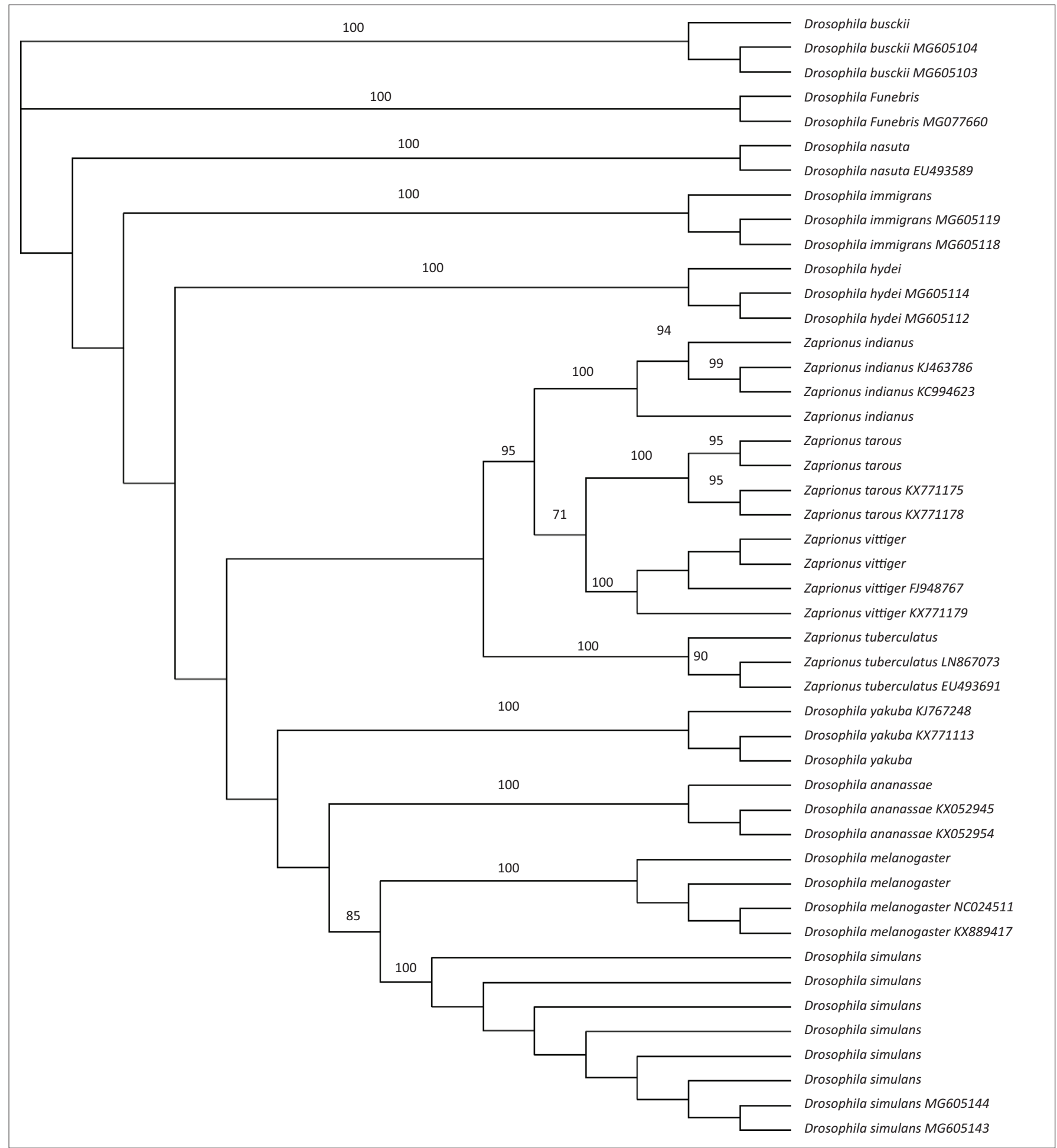

FIGURE 1: A phylogenetic tree based on maximum likelihood showing the relationships between the 13 Drosophilidae species collected in this study and reference specimens downloaded from National Center for Biotechnology Information (NCBI) (with accession numbers next to species names).The neighbour-joining tree has the same topology. Values on branches indicate bootstrap values (only values above $70 \%$ shown) calculated over 1000 replicates.

\section{Conclusion}

Although there are 70 Drosophilidae species known from South Africa (Tsacas 1990), little is known about the current composition of species nor how this varies across space and through time. From our limited effort of a small number of sites with few traps, three of the 13 species we identified were found to be first records for South Africa. This highlights the importance of surveying Drosophilidae in various biomes, and across seasons or climatic conditions, and using diverse baiting methods to capture the full range of species diversity in the family. With improved knowledge of species composition, species interactions and natural diets (land/ habitat use) and other ecological functions, the potential impacts of invasive species in this group can be better understood. 

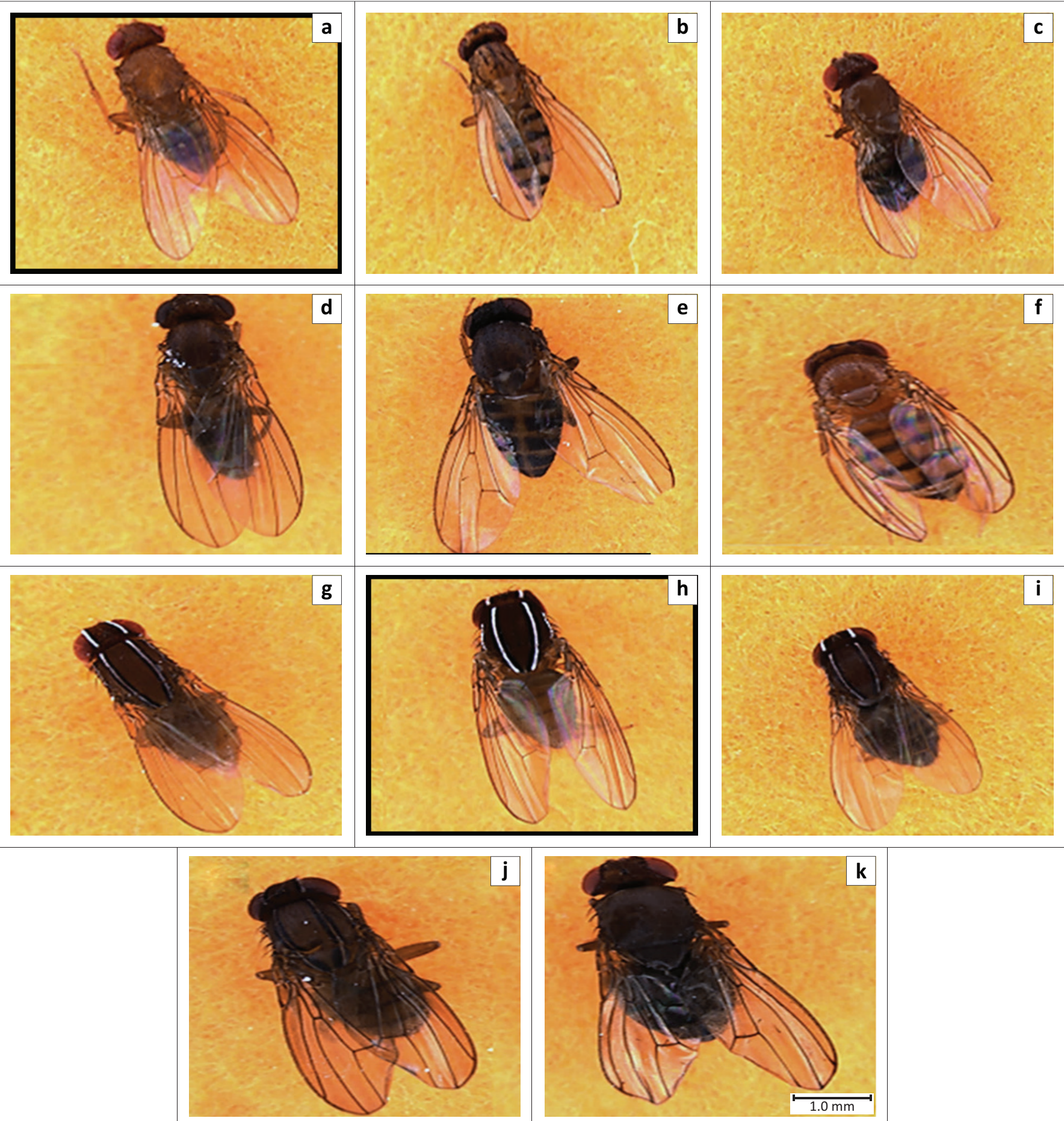

FIGURE 2: Eleven of the 13 Drosophilidae species sampled across South Africa. (a) Drosophila ananassae, female; (b) D. busckii, female; (c) D. melanogaster, female (d) D. funebris, male; (e) D. hydei, male; (f) D. simulans, female; (g) Zaprionus indianus, female; (h) Z. taronus, male; (i) Z. tuberculatus, male; (j) Z. vittiger, male; and (k) D. immigrans, female. Note all species are represented at a shared scale of $1 \mathrm{~mm}$. Black boxes indicate the species that are new records for South Africa; there is no image available for D. nasuta and D. yakuba.

\section{Acknowledgements}

The authors are grateful to Matroosberg Private Nature Reserve, South African Sugarcane Research Institute (SASRI), Stellenbosch University Botanical Gardens, Tania Vergnani and Jan Coetzee who allowed sampling on their properties. Their special thanks go to Dr Shane McEvey for assistance with species identifications. L.I.D.A. was supported by a
Centre for Invasion Biology (C.I.B) postgraduate bursary and M.K. by HORTGRO and SATI.

\section{Competing interests}

The authors declare that they have no financial or personal relationships that may have inappropriately influenced them in writing this article. 


\section{Authors' contributions}

M.K. and J.S.T. conceived the project; L.I.D.A., M.K. and J.S.T. secured funding; L.D.A. performed experimental work and gathered data; L.I.D.A., M.K. and J.S.T. analysed the data and co-wrote the article.

\section{Funding}

This research was funded by the Centre for Invasion Biology (C.I.B), Stellenbosch University, South Africa.

\section{Disclaimer}

The views and opinions expressed in this article are those of the authors and do not necessarily reflect the official policy or position of any affiliated agency of the authors.

\section{References}

Altschul, S.F., Madden, T.L., Schäffer, A.A., Zhang, J., Zhang, Z., Miller, W. et al., 1997 'Gapped BLAST and PSI-BLAST: A new generation of protein database search programs', Nucleic Acids Research 25, 3389-3402. https://doi.org/10.1093/nar/25.17.3389

Farnsworth, D., Hamby, K.A., Bolda, M., Goodhue, R.E., Williams, J.C. \& Zalom, F.G., 2017 'Economic analysis of revenue losses and control costs associated with the spotted
wing drosophila, Drosophila suzukii (Matsumura), in the California raspberry industry', wing drosophila, Drosophila suzukii (Matsumura), in the California raspberry ind
Pest management Science 73, 1083-1090. https://doi.org/10.1002/ps.4497
Folmer, O., Black, M., Hoeh, W., Lutz, R. \& Vrijenhoek, R., 1994, 'DNA primers for amplification of mitochondrial cytochrome $c$ oxidase subunit I from diverse metazoan invertebrates', Molecular Marine Biology and Biotechnology 3 metazoan $294-299$.

Hall, T.A., 1999, 'BioEdit: A user-friendly biological sequence alignment editor and analysis program for Windows 95/98/NT', Nucleic Acids Symposium Series 41, 95-98.

Hewitt, V.L. \& Whitworth, A.J., 2016, 'Chapter five-mechanisms of Parkinson's disease: Lessons from Drosophila', Current Topics in Developmental Biology 121, 173-200. https://doi.org/10.1016/bs.ctdb.2016.07.005

Kumar, S., Stecher, G., Li, M., Knyaz, C. \& Tamura, K., 2018, 'MEGA X: Molecular evolutionary genetics analysis across computing platforms', Molecular Biology and Evolution 35, 1547-1549. https://doi.org/10.1093/molbev/msy096

McEvey, S.F., Potts, A. \& Rogers, G., 1988, 'A key to Drosophilidae (Insecta: Diptera) collected in areas of human settlement in southern Africa', Journal of the Entomological Society of Southern Africa 51, 171-182.

Prigent, S.R., Suwalski, A. \& Veuille, M., 2017, 'Connecting systematic and ecological studies using DNA barcoding in a population survey of Drosophilidae (Diptera) from Mt Oku (Cameroon)', European Journal of Taxonomy 287, 1-20. https://doi. org/10.5852/ejt.2017.287

Tsacas, L., 1990, 'Drosophilidae de l'Afriqueaustrale (Diptera)', Annals of the Natal Museum 31, 103-161.

Vilela, C.R. \& Goñi, B., 2015, 'Is Drosophila nasuta Lamb (Diptera, Drosophilidae) currently reaching the status of a cosmopolitan species?', Revista Brasileira de Entomologia 59, 346-350. https://doi.org/10.1016/j.rbe.2015.09.007

Yassin, A. \& David, J.R., 2010, 'Revision of the Afrotropical species of Zaprionus (Diptera, Drosophilidae), with descriptions of two new species and notes on internal reproductive structures and immature stages', Zookeys 51, 33-72. https://doi.org/10.3897/zookeys.51.380

Yassin, A., Markow, T.A., Narechania, A., O'Grady, P.M. \& DeSalle, R., 2010, 'The genus Drosophila as a model for testing tree-and character-based methods of species identification using DNA barcoding', Molecular Phylogenetics and Evolution 57, 509-517. https://doi.org/10.1016/j.ympev.2010.08.020 